\title{
Response of low-strength phenol-acclimated activated sludge to shock loading of high phenol concentrations
}

\author{
Jun-Wei Lim ${ }^{1,2}$, Chye-Eng Seng ${ }^{1 *}$, Poh-Eng Lim', Si-Ling Ng ${ }^{3}$, Kui-Chew Tan and Sook-Ling Kew ${ }^{1}$ \\ 'School of Chemical Sciences, Universiti Sains Malaysia, 11800 Penang, Malaysia \\ 2Department of Environmental Engineering, Faculty of Engineering and Green Technology (FEGT), University Tunku Abdul Rahman, \\ 31900 Kampar, Perak, Malaysia \\ ${ }^{3}$ School of Science, Monash University Sunway Campus, 46150 Petaling Jaya, Selangor, Malaysia
}

\begin{abstract}
The objectives of this study were to: (i) evaluate the growth of low-strength phenol-acclimated activated sludge, (ii) investigate the degradation pathways and (iii) model the growth and biodegradation kinetics, all under the condition of increasingly higher phenol concentrations (step-up shock loading). With the use of activated sludge acclimated to phenol concentration of $140 \mathrm{mg} \cdot \ell^{-1}$ (low-strength phenol-acclimated activated sludge), complete degradation of phenol with a COD removal efficiency of more than $95 \%$ was achieved up to $1050 \mathrm{mg} \cdot \ell^{-1}$ of initial phenol concentration. At low initial phenol concentrations, the experimental results were indicative of the meta-cleavage pathway for phenol degradation. When the initial phenol concentration was above $630 \mathrm{mg} \cdot \ell^{-1}$, the degradation results were indicative of both meta- and ortho-cleavage pathways. The values of the Haldane kinetic parameters indicated a low degree of inhibition exerted by the presence of increasing phenol concentration. This was substantiated by the observation that the rate constant of phenol removal decreased by only $33 \%$ even though the initial phenol concentration was increased by 15 times from 70 to $1050 \mathrm{mg} \cdot \ell^{-1}$. Thus, the activated sludge acclimated to only $140 \mathrm{mg} \cdot \ell^{-1}$ of phenol could successfully treat up to $1050 \mathrm{mg} \cdot \ell^{-1}$ of phenol without experiencing complete inhibition during the degradation process.
\end{abstract}

Keywords: Phenol removal, low-strength phenol-acclimated activated sludge, degradation pathway, Haldane kinetic parameter

\section{INTRODUCTION}

Phenol is found in the effluents discharged from many industries, including petroleum refining, resin and plastics, chemical and petrochemical, coke ovens, pharmaceuticals and agro-industrial industries. Because of phenol's high toxicity effects and suspected carcinogenicity to living organisms even at low concentrations, its presence, especially in aqueous media, is stringently limited by regulations. The World Health Organization (WHO) has set a limit level of $1 \mathrm{mg} \cdot \ell^{-1}$ to regulate the phenol concentration in drinking waters (Nuhoglu and Yalcin, 2005; Kilic, 2009).

Biological treatment processes for phenol have been shown to be more cost-effective, practical and highly reliable as they lead to a low possibility of by-product formation (Lim et al., 2013). Batch and continuous processes using either pure or mixed cultures are employed for the treatment of phenolcontaining wastewaters (Buitron and Gonzalez, 1996; Yeom et al., 1997; Gonzalez et al., 2001; Gallego et al., 2003; Moharikar and Purohit, 2003; Chan and Lim, 2007; Kobayashi et al., 2007; Yang and Lee, 2007; Zhao et al., 2009; Saravanan et al., 2011). Mixed cultures have been shown to be more efficient when the emphasis is placed on the complete mineralisation of toxic organic compounds. Many pure culture studies have revealed that toxic intermediates accumulate during the biodegradation process leading to low COD removal efficiency (Saiqa et al., 1998; Wang and Loh, 1999; Dos Santos et al.,

To whom all correspondence should be addressed. 푱 +604 6533546; fax: +604 6574854; e-mail: ceseng@usm.my Received 18 October 2012; accepted in revised form 7 October 2013.
2009; Banerjee and Ghoshal, 2010). Therefore, the treatment of phenol in industrial effluents using activated sludge process in which a mixed culture is in action would be more meaningful, informative and practical. The main advantage achieved by the microbial consortium formed is the interaction among all the species present in the floc. The structure and toxicity differences among the phenolic compounds or intermediates produced during the degradation can be further mineralised by the mixed culture containing various bacteria with specific qualities. Kim et al. (2002) had documented that the degradation of phenol and 4-chlorophenol by Pseudomonas testosteroni CPW301 was seriously inhibited by 2,4,6-trichlorophenol. However, a mixed culture of Pseudomonas testosteroni CPW301 and Pseudomonas solanacearum TCP114 (which could only degrade 2,4,6-trichlorophenol) could treat phenol, 4-chlorophenol and 2,4,6-trichlorophenol completely and overcome the inhibition of substrates to other microorganisms.

Industrial wastewaters can contain phenol concentrations across a wide range (1-3 $000 \mathrm{mg} \cdot \ell^{-1}$ ) (Banerjee and Ghoshal, 2010). Sudden increases of concentration (shock loads) commonly occur and are responsible for disruption in industrial wastewater treatment facilities inoculated with low-strength phenol-acclimated activated sludge. As the growth of this low-strength phenol-acclimated activated sludge towards the biodegradation of wastewater laden with high phenol concentrations is not well understood, further investigation is deemed necessary.

Aerobes are basically more efficient in degrading phenol because they grow faster than anaerobes. During aerobic degradation, phenol is initially converted to catechol. Cleavage of the catechol is typically achieved via ortho- (intradiol) or meta- (extradiol) pathways, leading to the formation of 
cis, cis-muconic acid or 2-hydroxymuconic semialdehyde (2-HMSA), respectively. Cis, cis-muconic acid is converted into muconolactone for ortho-cleavage and 2-HMSA is either oxidised to 4-oxalocrotonate or hydrolysed to 2-oxopent-4-enoate in the case of meta-cleavage (Lin et al., 2000; Banerjee and Ghoshal, 2010). The products of both ortho- and meta-cleavage pathways are further metabolised in the tricarboxylic acid cycle (TCA). Nevertheless, the degradation pathways might change with a variation of initial concentrations of phenol (Loh and Chua, 2002). Thus, verification on similar pathways followed by low-strength phenol-acclimated activated sludge during biodegradation is necessary, as the phenol concentration in real wastewater can fall within a wide range.

During most periods, industrial bioremediation systems receive effluents containing low concentrations of phenol, leading to the development of low-strength phenol-acclimated activated sludge. It is therefore crucial to understand the response of the low-strength phenol-acclimated activated sludge when treating wastewater loaded with high phenol concentrations (shock loading condition). Many previous studies have concentrated on the treatment of phenol at concentrations lower than the acclimated concentrations (Saravana et al., 2008; Ng et al., 2009; Cristen et al., 2012). Therefore, the objectives of this study were to:

- Evaluate the growth of low-strength phenol-acclimated activated sludge

- Investigate the degradation pathways

- Model the growth and biodegradation kinetics, all under the condition of increasingly higher phenol concentrations (step-up shock loading).

\section{EXPERIMENTAL}

\section{Culturing of low-strength phenol-acclimated activated sludge}

The activated sludge used in the batch experiments was collected from a municipal sewage treatment plant in Penang. The activated sludge was then cultured in a sequencing batch reactor (SBR) of $12.8 \ell$ working volume with a base mix of the following composition (mg. $\left.\ell^{-1}\right)$ : peptone (32), sucrose (109), $\mathrm{CH}_{3} \mathrm{COONa}$ (56), $\left(\mathrm{NH}_{4}\right)_{2} \mathrm{SO}_{4}(405), \mathrm{KH}_{2} \mathrm{PO}_{4}(35), \mathrm{K}_{2} \mathrm{HPO}_{4}$ (180), $\mathrm{MgSO}_{4}$ (49), $\mathrm{NaHCO}_{3}(354), \mathrm{FeCl}_{3} \cdot 6 \mathrm{H}_{2} \mathrm{O}$ (10) and $\mathrm{CaCl}_{2}$ (42). The reactor was operated with the following sequences: instantaneous FILL, 0 h; REACT, 12 h; SETTLE, 1.5 h; DRAW, $1 \mathrm{~h}$ and IDLE, $9.5 \mathrm{~h}$ for a cycle time of $24 \mathrm{~h}$. During each cycle, $9 \ell$ of base mix was introduced into the reactor and the same volume of treated effluent was withdrawn during the DRAW period. The sludge age was maintained at 40 days by wasting an appropriate amount of mixed liquor at the end of the REACT period. After the attainment of the steady state, the base mix was spiked with phenol so that the phenol concentration in the mixed liquor during the initial REACT period was $140 \mathrm{mg} \cdot \ell^{-1}$. Upon reaching the quasi-steady state, which took about 5 months, the mixed liquor volatile suspended solids (VSS) concentration in the SBR was determined according to Standard Methods (APHA, 1998) and found to be $4500 \pm 100 \mathrm{mg} \cdot \ell^{-1}$.

\section{Batch experiments}

After attaining the quasi-steady state (defined as a fairly constant reaction time for the complete mineralisation of phenol), activated sludge suspension samples which were obtained from the SBR at the end of the REACT period to avoid the presence of carbonaceous matter were used for the batch experiments in the following sections. The samples contained activated sludges which had been acclimated to the base mix (phenolunacclimated activated sludge) and phenol-containing-base mix (phenol-acclimated activated sludge), respectively.

\section{Specific oxygen uptake rate}

In the specific oxygen uptake rate (SOUR) measurement, $50 \mathrm{~m} \ell$ of both phenol-acclimated and unacclimated activated sludges were aerated until saturated with dissolved oxygen (DO). The activated sludge was then poured into several BOD bottles containing $260 \mathrm{ml}$ of base mix. The bioactivity of the phenol-acclimated and unacclimated activated sludges in terms of SOUR were studied with increasing initial concentrations of phenol from 0 to $1050 \mathrm{mg} \cdot \ell^{-1}$. The change of DO concentration with time in each bottle was measured at $10 \mathrm{~s}$ time intervals using a DO meter (YSI 550A) with adequate mixing provided by a magnetic stirrer. After the DO measurement, the sample was filtered for VSS determination. The SOUR of each sample was calculated by dividing the slope of the DO decline curve with the VSS concentration in the bottle.

\section{Phenol degradation study in batch reactors}

The phenol degradation experiment was conducted in a beaker filled with $1.4 \ell$ of base mix. Low-strength phenol-acclimated activated sludge suspension cultured earlier was then added into the beaker to attain a VSS concentration of $800 \pm 50 \mathrm{mg} \cdot \ell^{-1}$, with a total working volume of $2 \ell$. The mixed liquor was immediately agitated with a magnetic stirrer. The degradation experiment was carried out by varying the initial phenol concentration from 0 to $1050 \mathrm{mg} \cdot \ell^{-1}$. The $\mathrm{pH}$ and DO were maintained in the ranges of $7.5 \pm 0.3$ and $6.0 \pm 0.5 \mathrm{mg} \cdot \ell^{-1}$, respectively, throughout the reaction period. Frequent sampling was conducted for the determination of phenol and COD concentrations until phenol was completely degraded in the mixed liquor. The phenol concentrations were measured spectrophotometrically by the colorimetric 4-aminoantipyrine method at a wavelength of $500 \mathrm{~nm}$, as described by Standard Methods (APHA, 1998). The COD concentrations were also determined according to Standard Methods (APHA, 1998) using the closed reflux and titrimetric method. The biomass growth in terms of VSS concentration was also monitored via optical density (OD) measurement at $600 \mathrm{~nm}$ (Wang and Loh, 1999; Cui and Li, 2009). In addition, the samples were scanned in the UV region for the presence of intermediate products during the phenol degradation period. Abiotic experiments using autoclaved activated sludge for all the phenol concentrations studied under the same conditions were conducted to determine the removal of phenol via other processes such as volatilisation and adsorption. It was found that the total phenol loss due to physical processes was less that $4 \%$ for all the batch experiments performed.

\section{RESULTS AND DISCUSSION}

\section{Bioactivity of the activated sludge}

The mean SOUR values for both phenol-acclimated and unacclimated activated sludges are shown in Fig. 1. The results were based on 3 determinations and the standard deviations are shown as the error bars. In the absence of phenol, the SOUR values for both acclimated and unacclimated activated sludges were approximately $122 \mathrm{mg}^{-\mathrm{O}_{2}} \mathrm{~g} \mathrm{VSS}^{-1} \mathrm{~h}^{-1}$. When the initial 


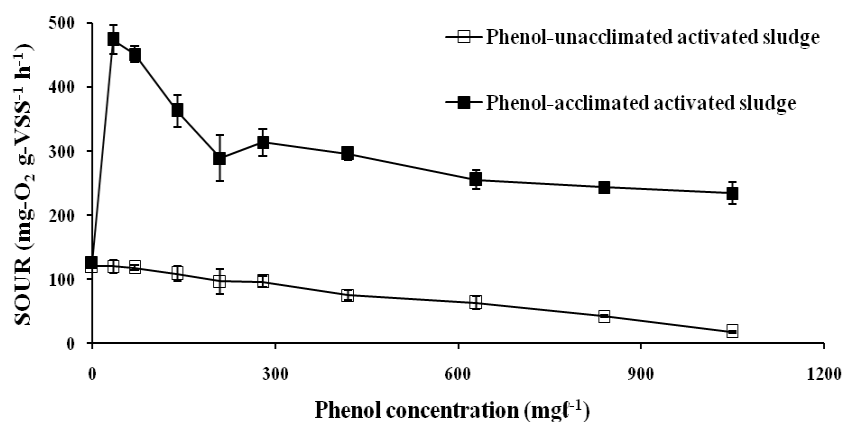

Figure 1

Variation of mean SOUR values with different initial phenol concentrations for phenol-acclimated and unacclimated activated sludges. Error bars indicate standard deviations.

concentration of phenol was $35 \mathrm{mg} \ell^{-1}$, the SOUR for phenolacclimated sludge increased to around $473 \mathrm{mg}^{-} \mathrm{O}_{2} \mathrm{~g}_{-} \mathrm{VSS}^{-1} \mathrm{~h}^{-1}$. Increasing the initial concentration of phenol to $210 \mathrm{mg} \cdot \ell^{-1}$ resulted in a progressive decrease of the SOUR for the phenolacclimated sludge to about $288 \mathrm{mg}-\mathrm{O}_{2} \mathrm{~g}_{-V_{S S}}^{-1} \mathrm{~h}^{-1}$. In spite of a further increase of the initial phenol concentration to $1050 \mathrm{mg} \cdot \ell^{-1}$, the SOUR value was found to decrease by only $13 \%$ to about $250 \mathrm{mg}-\mathrm{O}_{2}{\mathrm{~g}-\mathrm{VSS}^{-1}}^{-1}$. In contrast, the SOUR value for the unacclimated sludge decreased by $84 \%$ to $20 \mathrm{mg}^{-\mathrm{O}_{2}} \mathrm{~g} \mathrm{VSS}^{-1} \mathrm{~h}^{-1}$ for the corresponding increase of phenol concentration. Overall, the results show that the bioactivity of the acclimated sludge, despite being acclimated to relatively low phenol concentrations, was only slightly affected by the shock loading of higher phenol concentrations.

\section{Phenol degradation}

Removal efficiency profiles of phenol and COD at various initial phenol concentrations by acclimated activated sludge are shown in Figs. 2a and 2b, respectively. It was observed that phenol was completely degraded in all the concentrations studied without any observable lag phase, even though the initial concentration of phenol was as high as $1050 \mathrm{mg} \cdot \ell^{-1}$. During the biodegradation, COD removal efficiencies of more than $95 \%$ were attained in all the batch experiments studied. In contrast, initial phenol concentrations of only $15 \mathrm{mg} \cdot \ell^{-1}$ were capable of inhibiting the phenol-unacclimated activated sludge. A lag phase of $2 \mathrm{~h}$ could be observed before phenol was completely degraded at the end of $8 \mathrm{~h}$. These results further underscore the importance of acclimation processes in the biodegradation of phenol.

\section{Degradation pathway}

The UV absorption at $375 \mathrm{~nm}$ has been reported to be assigned to 2-HMSA (Saiqa et al., 1998; Banerjee and Ghoshal, 2010). This peak appeared in the UV spectra for all the phenol concentrations studied, confirming that meta-cleavage was taking place. In this study, the absorbance at $375 \mathrm{~nm}$ was found to increase with the increase of initial phenol concentrations, indicating the accumulation of 2-HMSA during the phenol degradation process, but complete degradation of 2-HMSA was achieved in all cases (Fig. 3a). When the initial phenol concentration was increased to $420 \mathrm{mg} \cdot \ell^{-1}$, another peak started to appear at $292 \mathrm{~nm}$. These spectral characteristics were consistent with those reported for 4-oxalocrotonate which was produced from the oxidation of 2-HMSA catalysed by 2-hydroxymuconic
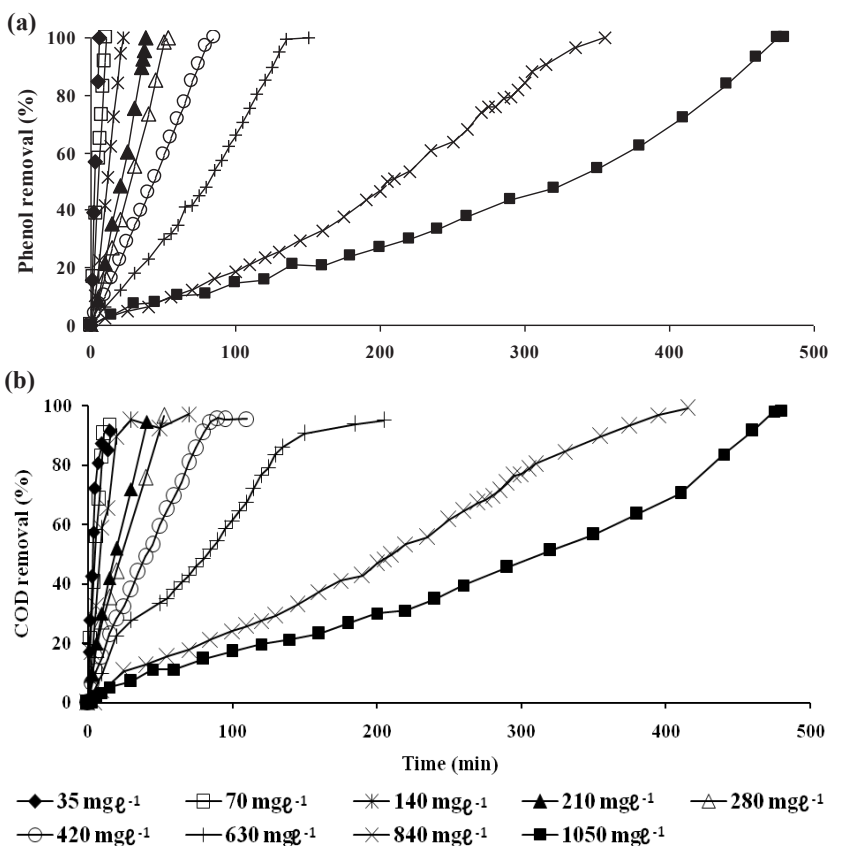

Figure 2

Removal profiles for (a) phenol and (b) COD for different initial phenol concentrations
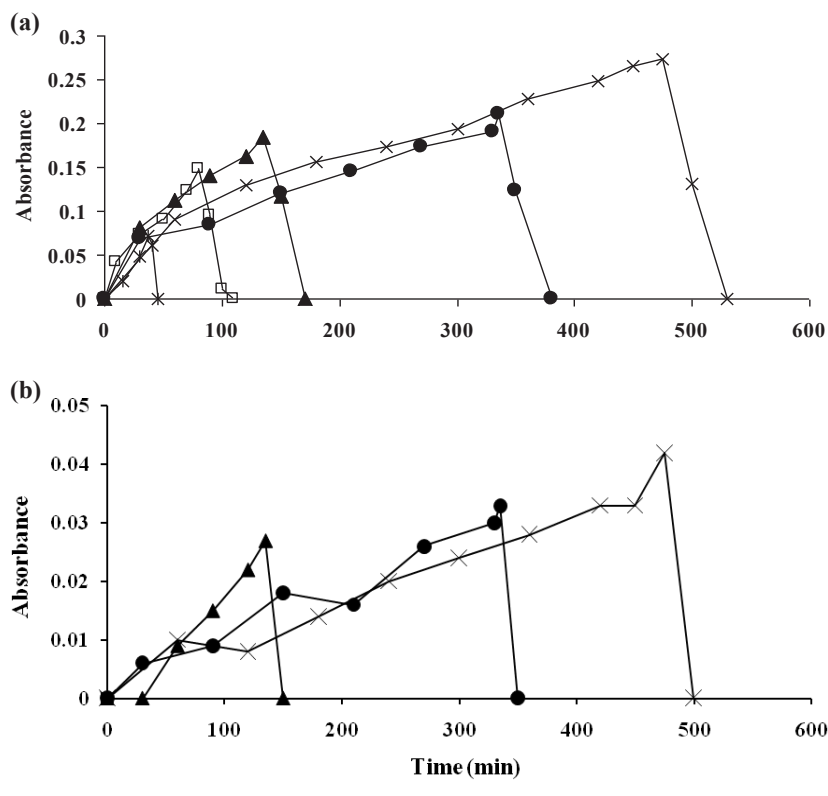

* $210 \mathrm{mg} \ell^{-1} \leftarrow 420 \mathrm{mg} \ell^{-1} \leftarrow 630 \mathrm{mg} \ell^{-1} \multimap-840 \mathrm{mg} \ell^{-1} \leftarrow 1050 \mathrm{mg} \ell^{-1}$

Figure 3

Time courses of (a) 2-HMSA and (b) cis, cis-muconic acid concentrations for different initial phenol concentrations

semialdehyde dehydrogenase (Adams and Ribbons, 1988; Banerjee and Ghoshal, 2010). The appearance of the peak related to 4-oxalocrotonate was indicative of phenol degradation via the meta-cleavage pathway for all the phenol concentrations studied.

Increase of initial phenol concentrations from $630 \mathrm{mg} \cdot \ell^{-1}$ onwards led to the emergence of another peak at $260 \mathrm{~nm}$. This peak was indicative of the existence of cis, cis-muconic 
acid originated from the ortho-cleavage pathway (Wu et al., 2004; Banerjee and Ghoshal, 2010). Figure 3b shows that this intermediate compound was completely degraded in all cases studied, though complete degradation was only achieved at a relatively longer period for higher initial phenol concentrations. Thus, at higher phenol concentrations, simultaneous activation of catechol-1,2-dioxygenase and catechol-2,3-dioxygenase, which promote both ortho- and meta-cleavage pathways, respectively, was induced to enhance and facilitate phenol degradation process. These findings were contrary to the observations made by Loh and Chua (2002) in their study with the pure culture of Pseudomonas putida ATCC 49451. They reported that catechol was initially oxidised via the orthocleavage instead of meta-cleavage pathways. Besides, simultaneous activation of catechol-1,2-dioxygenase and catechol-2,3dioxygenase were induced at sodium benzoate concentrations of only $300 \mathrm{mg} \cdot \ell^{-1}$. However, in the present study, simultaneous activation of the enzymes occurred at the phenol concentration as high as $630 \mathrm{mg} \cdot \ell^{-1}$ thus proving a better endurance of mixed culture towards phenolic compounds as compared to pure culture. Loh and Chua (2002) also reported the accumulation of 2-HMSA as it was not degraded with pure culture. In contrast, this meta-cleavage intermediate was found to be completely mineralised with mixed culture (acclimated to initial phenol concentration of only $\left.140 \mathrm{mg} \cdot \ell^{-1}\right)$ in this study, as evidenced by the disappearance of the absorbance value at $375 \mathrm{~nm}$ in UV spectra and the COD removal efficiencies of close to $100 \%$ for all the batch experiments (Fig. 2b).

\section{Kinetic studies}

The biodegradation of phenol has generally been known to be inhibited by phenol itself, especially at high concentration. Thus, the Monod kinetic model for non-inhibitory substrates is inadequate to predict the phenol biodegradation precisely. In this study, the Haldane model has been selected for describing the growth kinetics of phenol-acclimated activated sludge. The Haldane equation is given as:

$$
\mu=\frac{\mu_{\max } S_{o}}{K_{s}+S_{o}+\left(\frac{S_{o}^{2}}{K_{i}}\right)}
$$

where:

$$
\begin{aligned}
& S_{o} \text { is the initial substrate concentration }\left(\mathrm{mg} \cdot \ell^{-1}\right) \\
& \mu_{\max } \text { is the maximum specific growth rate }\left(\mathrm{h}^{-1}\right) \\
& K_{s} \text { is the half-saturation constant }\left(\mathrm{mg} \cdot \ell^{-1}\right) \\
& K_{i} \text { is the substrate inhibition constant }\left(\mathrm{mg} \cdot \ell^{-1}\right) .
\end{aligned}
$$

A large $K_{i}$ value indicates that the microorganisms are less sensitive to substrate inhibition (Nuhoglu and Yalcin, 2005; Ho et al., 2009; Banerjee and Ghoshal, 2010). The biomass concentration versus time (growth profile) during phenol degradation at various initial phenol concentrations is shown in Fig. 4. The specific growth rate $(\mu)$ was then determined by performing a linear fit on the exponential growth phase of the growth profile.

The Haldane equation was used to fit the experimental data of $\mu$ versus $S_{o}$ using MATLAB 7.0.4 and the results are shown in Fig. 5. The values of the three kinetic parameters generated from the fitting of the Haldane model are $\mu_{\max }=0.920 \mathrm{~h}^{-1}, K_{s}=$ $2.64 \mathrm{mg} \cdot \ell^{-1}$ and $K_{i}=2623 \mathrm{mg} \cdot \ell^{-1}\left(R^{2}=0.998 ; \mathrm{SSE}=0.0008612\right.$; RMSE $=0.01109$ ). The good fit of the experimental data to the Haldane model can be explained by the fact that the interim accumulated intermediates were completely degraded as soon as the phenol was degraded, as shown in Fig. 3. Nuhoglu and

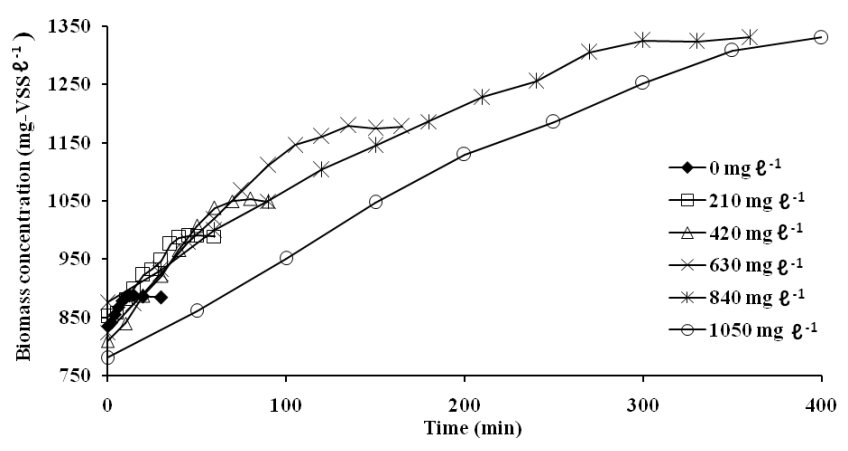

Figure 4

Biomass growth profiles at different initial phenol concentrations

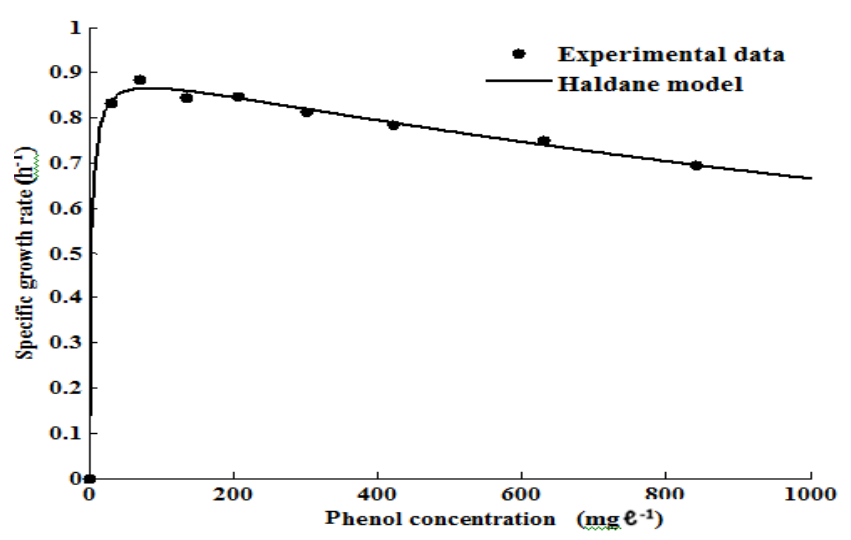

Figure 5

Experimental and Haldane predicted specific growth rates at different initial phenol concentrations

\begin{tabular}{|l|l|l|l|l|}
\hline \multicolumn{5}{|c|}{ TABLE 1 } \\
\multicolumn{5}{|c|}{$\begin{array}{c}\text { Comparison of Haldane growth kinetic constants and } \\
\boldsymbol{K}_{s} / \boldsymbol{K}_{i} \text { ratios in various studies on phenol degradation }\end{array}$} \\
\hline $\boldsymbol{\mu}_{\max }\left(\mathbf{h}^{-1}\right)$ & $K_{s}\left(\mathbf{m g} \cdot \ell^{-1}\right)$ & $K_{i}\left(\mathbf{m g} \cdot \ell^{-1}\right)$ & $K_{s} / K_{i}$ & Reference \\
\hline 0.920 & 2.64 & 2623 & 0.001 & This study \\
\hline 0.897 & 12.2 & 204 & 0.601 & Dikshitulu et al. (1993) \\
\hline 0.456 & 53.9 & 516 & 0.104 & $\begin{array}{l}\text { Kumaran and Paruchuri } \\
(1997)\end{array}$ \\
\hline 0.436 & 6.20 & 54 & 0.114 & Monteiro et al. (2000) \\
\hline 0.143 & 87.5 & 107 & 0.817 & $\begin{array}{l}\text { Nuhoglu and Yalcin } \\
(2005)\end{array}$ \\
\hline 0.026 & 29.3 & 2435 & 0.012 & Arutchelvan et al. (2006) \\
\hline 0.438 & 29.5 & 72 & 0.410 & Marrot et al. (2006) \\
\hline 0.054 & 19.2 & 37 & 0.519 & Tziotzios et al. (2008) \\
\hline 0.310 & 74.6 & 647 & 0.115 & Bajaj et al. (2009) \\
\hline 0.656 & 33.1 & 1470 & 0.023 & Ho et al. (2009) \\
\hline 0.119 & 11.1 & 251 & 0.044 & Ucun et al. (2010) \\
\hline
\end{tabular}

Yalcin (2005) had found that these accumulated metabolic intermediates were capable of exerting an additional inhibition effect leading to the inadequacy of the Haldane equation.

The degree of substrate inhibition is more appropriately reflected by the $K_{s} / K_{i}$ ratio rather than $K_{i}$ alone (Nuhoglu and Yalcin, 2005). A greater degree of inhibition is reflected by the larger $K_{s} / K_{i}$ ratio. The Haldane growth kinetic constants and $K_{s} / K_{i}$ ratio obtained in this study were compared with those in other studies (Table 1). It was observed that the $\mu_{\max }$ and $K_{i}$ 


\section{TABLE 2}

Mean values of pseudo-zero-order rate constants for phenol removal at different initial phenol concentrations

\begin{tabular}{|c|c|c|}
\hline Phenol $\left(\mathbf{m g} \cdot \ell^{-1}\right)$ & $\boldsymbol{k}_{p h}\left(\mathbf{m g} \cdot \boldsymbol{\ell}^{-1} \cdot \mathbf{m i n}^{-1}\right)$ & $\boldsymbol{R}^{2}$ \\
\hline 35 & $5.8 \pm 0.2$ & 0.996 \\
\hline 70 & $6.3 \pm 0.0$ & 0.998 \\
\hline 140 & $6.2 \pm 0.4$ & 0.996 \\
\hline 210 & $5.4 \pm 0.5$ & 0.998 \\
\hline 280 & $5.8 \pm 0.8$ & 0.997 \\
\hline 420 & $5.4 \pm 0.5$ & 0.995 \\
\hline 630 & $4.9 \pm 0.3$ & 0.980 \\
\hline 840 & $4.5 \pm 0.3$ & 0.945 \\
\hline 1050 & $4.2 \pm 0.3$ & 0.945 \\
\hline
\end{tabular}

values fall in the high end of the range of values reported in the literature, whereas the $K_{s}$ value lies at the low end. Thus, the results of the batch experiments indicated that low-strength phenol-acclimated activated sludge was able to grow in the initial phenol concentration range of $0-1050 \mathrm{mg} \cdot \ell^{-1}$ without experiencing any adverse inhibition, as illustrated by a relatively small $K_{s} / K_{i}$ ratio. The relatively high $K_{i}$ value as predicted from the Haldane model (Table 1) also indicated that phenol inhibition would only be initiated at phenol concentration higher that $2600 \mathrm{mg} \cdot \ell^{-1}$.

The near linearity of the data of phenol concentration versus time for various initial phenol concentrations reveals that the rate of phenol degradation may be described by zero-order kinetics. This can also be deduced from the Haldane model under the conditions of $K_{s}<S_{o}<K_{i}$. The pseudo-zero-order rate constant of phenol removal $\left(k_{P h}\right)$ was determined from the slope of the linear plot and the mean value from an average of 2determinations; the $R^{2}$ value for each of the initial phenol concentrations studied is shown in Table 2. It was observed that the fit became less satisfactory as the initial phenol concentration increased. The $k_{\mathrm{Ph}}$ attained the highest value when the initial phenol concentration was $70 \mathrm{mg} \cdot \ell^{-1}$. The rate constant gradually decreased with the increase of initial phenol concentration to a value higher than $70 \mathrm{mg} \cdot \ell^{-1}$. This trend is in agreement with what was observed for the specific growth rate, which achieved $\mu_{\max }$ at initial phenol concentration of $70 \mathrm{mg} \cdot \ell^{-1}$ (Fig. 5) and can be used to explain the trend of SOUR values for phenolacclimated activated sludge shown in Fig. 1. Thus, the effect of shock loading was felt at the initial phenol concentrations above $70 \mathrm{mg} \cdot \ell^{-1}$ which was manifested in the gradually decreasing degradation rate constant. Nevertheless, the rate constant of phenol removal decreased by only $33 \%$, despite an increase in the initial phenol concentration by 15 times from 70 to 1050 $\mathrm{mg} \cdot \ell^{-1}$, as shown in Table 2 .

\section{CONCLUSIONS}

With the use of low-strength phenol-acclimated activated sludge, complete degradation of phenol with a COD removal efficiency of more than $95 \%$ was achieved, up to an initial phenol concentration of $1050 \mathrm{mg} \cdot \ell^{-1}$. The results of phenol degradation were indicative of the meta-cleavage pathway for low initial phenol concentrations $\left(<630 \mathrm{mg} \cdot \ell^{-1}\right)$. However, when the initial phenol concentrations were above $630 \mathrm{mg} \cdot \ell^{-1}$, the results were indicative of both meta- and ortho-cleavage pathways. The biomass growth was well described by the Haldane model with the kinetic parameters $\mu_{\max }, K_{s}$ and $K_{i}$ having the values of $0.920 \mathrm{~h}^{-1}, 2.64 \mathrm{mg} \cdot \ell^{-1}$ and $2623 \mathrm{mg} \cdot \ell^{-1}$, respectively.
The relatively small $K / K$ ratio indicates low degree of inhibition in the phenol concentration range studied. The pseudozero-order rate constant decreased by only $33 \%$ even though the initial phenol concentration was increased by 15 times from 70 to $1050 \mathrm{mg} \cdot \ell^{-1}$. Therefore, the activated sludge acclimated to phenol concentrations of $140 \mathrm{mg} \cdot \ell^{-1}$ is anticipated to be able to treat wastewater containing phenol up to $1050 \mathrm{mg} \cdot \ell^{-1}$ without experiencing complete inhibition in actual practice, as predicted by the kinetic studies.

\section{ACKNOWLEDGEMENTS}

Financial support from the Universiti Sains Malaysia under the Research University (RU) Grant No: 1001/PKIMIA/814149 is gratefully acknowledged. Jun-Wei Lim wishes to acknowledge financial support from MyBrain 15 (MyPhD) programme.

\section{REFERENCES}

ADAMS D and RIBBONS DW (1988) The metabolism of aromatic ring fission products by Bacillus Stearothermophilus strain IC3. J. Gen. Microbiol. 134 3179-3185.

APHA (1998) Standard Methods for the Examination of Water and Wastewater (20 th $\mathrm{edn}$.). American Public Health Association, Washington, DC.

ARUTCHELVAN V, KANAKASABAI V, ELANGOVAN R, NAGARAJAN S and MURALIKRISHNAN V (2006) Kinetics of high strength phenol degradation using Bacillus brevis. J. Hazardous Mater. 129 216-222.

BAJAJ M, GALLERT C and WINTER J (2009) Phenol degradation kinetics of an aerobic mixed culture. Biochem. Eng. J. 46 205-209.

BANERJEE A and GHOSHAL AK (2010) Phenol degradation by bacillus cereus: pathway and kinetic modeling. Bioresour. Technol. 101 5501-5507.

BUITRON G and GONZALEZ A (1996) Characterization of the microorganisms from an acclimated activated sludge degrading phenolic compounds. Water Sci. Technol. 34 289-294.

CHAN CH and LIM PE (2007) Evaluation of sequencing batch reactor performance with aerated and unaerated FILL periods in treating phenol-containing wastewater. Bioresour. Technol. 98 1333-1338.

CHRISTEN P, VEGA A, CASALOT L, SIMON G and AURIA R (2012) Kinetics of aerobic phenol biodegradation by the acidophilic and hyperthermophilic archaeon Sulfolobus solfataricus 98/2. Biochem. Eng. J. 62 56-61.

CUI JD and LI Y (2009) Optimal culture condition for the production of phenyalanine ammonia lyase from E. coli. Korean J. Chem. Eng. $26444-448$.

DIKSHITULU S, BALTZIS BC, LEWANDOWSKI GA and PAVLOU $S$ (1993) Competition between two microbial populations in a sequencing fed-batch reactor: theory, experimental verification, and implications for waste treatment applications. Biotechnol. Bioeng. 42 643-656.

DOS SANTOS VL, DE SOUZA MONTEIRO A, BRAGA DT and SANTORO MM (2009) Phenol degradation by Aureobasidium pullulans FE13 isolated from industrial effluents. J. Hazardous Mater. 161 1413-1420.

GALLEGO A, FORTUNATO MS, FOGLIA J, ROSSI S, GEMINI V, GOMEZ L, GOMEZ CE, HIGA LE and KOROL SE (2003) Biodegradation and detoxification of phenolic compounds by pure and mixed indigenous cultures in aerobic reactors. Int. Biodeterior. Biodegrad. 52 261-267.

GONZALEZ G, HERRERA MG, GARCIA MT and PENA MM (2001) Biodegradation of phenol in a continuous process: Comparative study of stirred tank and fluidized-bed bioreactors. Bioresour. Technol. 76 245-251.

HO KL, LIN B, CHEN YY and LEE DJ (2009) Biodegradation of phenol using Corynebacterium sp. DJ1 aerobic granules. Bioresour. Technol. 100 5051-5055. 
KILIC NK (2009) Enhancement of phenol degradation by Ochrobactrum sp. isolated from industrial wastewaters. Int. Biodeterior. Biodegrad. 63 778-781.

KIM JH, OH KK, LEE ST, KIM SW and HONG SI (2002) Biodegradation of phenol and chlorophenols with defined mixed culture in shake-flasks and a packed bed reactor. Process Biochem. 37 1367-1373.

KOBAYASHI F, DAIDAI M, SUZUKI N and NAKAMURA Y (2007) Degradation of phenol in seawater using a novel microorganism isolated from the intestine of Aplysia kurodai. Int. Biodeterior Biodegrad. 59 252-254.

KUMARAN P and PARUCHURI TL (1997) Kinetics of phenol biotransformation. Water Res. 31 11-22.

LIM JW, TAN JZ and SENG CE (2013) Performance of phenolacclimated activated sludge in the presence of various phenolic compounds. Appl. Water Sci. DOI: 10.1007/s13201-013-0099-9.

LIN G, REID G and BUGG TDH (2000) A biomimetic model reaction for the extradiol catechol dioxygenases. Chem. Commun. 2000 1119-1120. DOI: 10.1039/B003625K.

LOH KC and CHUA SS (2002) Ortho pathway of benzoate degradation in Pseudomonas putida: induction of meta pathway at high substrate concentrations. Enzyme Microb. Technol. 30 620-626.

MARROT B, BARRIOS-MERTINEZ A, MOULIN P and ROCHE N (2006) Biodegradation of high phenol concentration by activated sludge in an immersed membrane bioreactor. Biochem. Eng. J. 30 174-183.

MOHARIKAR A and PUROHIT HJ (2003) Specific ratio and survival of Pseudomonas CF600 as co-culture for phenol degradation in continuous cultivation. Int. Biodeterior. Biodegrad. 52 255-260.

MONTEIRO AAMG, BOAVENTURA RAR and RODRIGUES AE (2000) Phenol biodegradation by Pseudomonas putida DSM 548 in a batch reactor. Biochem. Eng. J. 6 45-49.

NG SL, SENG CE and LIM PE (2009) Quantification of bioregeneration of activated carbon and activated rice husk loaded with phenolic compounds. Chemosphere 75 1392-1400.
NUHOGLU A and YALCIN B (2005) Modeling of phenol removal in a batch reactor. Process Biochem. 40 1233-1239.

SAIQA A, ROBERTO FL and DON AC (1998) Meta-pathway degradation of phenolics by thermophilic bacilli. Enzyme Microb. Technol. 23 462-468.

SARAVANAN P, PAKSHIRAJAN K and SAHA P (2008) Growth kinetics of an indigenous mixed microbial consortium during phenol degradation in a batch reactor. Bioresour. Technol. 99 205-209.

SARAVANAN P, PAKSHIRAJAN K and SAHA P (2011) Studies on growth kinetics of predominantly Pseudomonas sp. in internal loop airlift bioreactor using phenol and $m$-cresol. Korean J. Chem. Eng. 28 1550-1555.

TZIOTZIOS G, LYBERATOS G, PAVLOU S and VAYENAS DV (2008) Modelling of biological phenol removal in draw-fill reactors using suspended and attached growth olive pulp bacteria. Int. Biodeterior. Biodegrad. 61 142-150.

UCUN H, YILDIZ E and NUHOGLU A (2010) Phenol biodegradation in a batch jet loop bioreactor (JLB): kinetics study and $\mathrm{pH}$ variation. Bioresour. Technol. 101 2965-2971.

WANG SJ and LOH KC (1999) Modeling the role of metabolic intermediates in kinetics of phenol biodegradation. Enzyme Microb. Technol. 25 177-184.

WU CM, LEE TH, LEE SN, LEE YA and WU JY (2004) Microbial synthesis of cis, cis-muconic acid by Sphingobacterium sp. GCG generated from effluent of a styrene monomer (SM) production plant. Enzyme Microb. Technol. 35 598-604.

YANG CF and LEE CM (2007) Enrichment, isolation and characterization of phenol-degrading Pseudomonas resinovorans strain P-1 and Brevibacillus sp. strain P-6. Int. Biodeterior. Biodegrad. 59 206-210.

YEOM SH, KIM SH, YOO YJ and YOO IS (1997) Microbial adaptation in the degradation of phenol by Alcaligenes xylosoxidans Y234. Korean J. Chem. Eng. 14 37-40.

ZHAO Z, JIANG G, JIANG S and DING F (2009) Integrated anaerobic/aerobic biodegradation in an internal airlift loop reactor for phenol wastewater treatment. Korean J. Chem. Eng. 26 1662-1667. 